\title{
argestre
}

\section{Desenvolvimento e avaliação de aplicativo em boas práticas de manipulação de alimentos}

\author{
APPLICATION DEVELOPMENT AND ASSESSMENT ON GOOD FOOD HANDLING PRACTICES
}

Ariana dos Santos Souza', Rosângela Ochabel Bezerra Paiva Guerra², Mattheus
Adhonnay Sobral Feitosa ${ }^{3}$, Taisy Cinthia Ferro Cavalcante 4 , Claudileide de Sá Silva ${ }^{5}$

1 Graduanda em Nutrição. Universidade de Pernambuco.

Orcid: https://orcid.org/0000-0002-4633-0254.

E-mail: arianasouvza96@gmail.com

2 Graduanda em Nutrição. Universidade de

Pernambuco.

Orcid: https://orcid.org/0000-0002-1646-8789.

E-mail: rocha.pguerra@hotmail.com

3 Graduando em Engenharia da Computação. Universidade Federal do Vale do São Francisco. Orcid: https://orcid.org/0000-0001-8152-417X.

E-mail: mattheusadhonnaysf@hotmail.com

4 Doutora em Nutrição. Universidade Federal de

Pernambuco/ Universidade de Pernambuco.

Orcid: https://orcid.org/0000-0002-6498-5158.

E-mail: taisy.cavalcante@upe.br

5 Doutora em Ciência e Tecnologia de Alimentos.

Universidade Federal do Pará/ Universidade de Pernambuco.

Orcid: http://lattes.cnpq.br/0449463456141164.

E-mail: claudileide.silva@upe.br

Correspondência: UPE, Universidade de Pernambuco. Colegiado de Nutrição - Rodovia BR 203, Km 2 s/n Vila Eduardo, Petrolina - PE, Brasil. CEP: 56328-900.

Copyright: Esta obra está licenciada com uma Licença Creative Commons Atribuição-NãoComercial 4.0 Internacional.

Conflito de interesses: os autores declaram que não há conflito de interesses.

\section{Como citar este artigo}

Souza A dos Santos; Guerra ROBP; Feitosa MAS; Cavalcante TCF; Silva $C$ de Sá. Desenvolvimento e avaliação de aplicativo em boas práticas de manipulação de alimentos. Revista de Saúde Digital e Tecnologias Educacionais. [online], volume 5, n. 2. Editor responsável: Luiz Roberto de Oliveira. Fortaleza, julho de 2020, p. 44-57. Disponível em: http://periodicos.ufc.br/resdite/index. Acesso em "dia/mês/ano".

Data de recebimento do artigo: 10/01/2020

Data de aprovação do artigo: 26/06/2020

Data de publicação: 20/07/2020

\section{Resumo}

Introdução: Avanços na tecnologia são canais promotores de conhecimentos, podendo contribuir para o setor da saúde. Sendo a alimentação, a manipulação segura dos alimentos e a nutrição requisitos básicos para a promoção da saúde, as tecnologias são uma boa alternativa para fornecer informações atualizadas sobre alimentação. Referencial teórico: Este estudo ancora-se no princípio da segurança alimentar e nutricional ${ }^{8}$. Objetivo: Relatar a construção e avaliação de um aplicativo para divulgação das boas práticas de manipulação de alimentos. Método: Selecionaram-se cinco categorias para compor o APP, com cinco seções cada. A programação do aplicativo SafeFood foi desenvolvida na linguagem Java Script e no framework React Native. Para avaliar a aceitação do aplicativo e o conhecimento dos participantes, elaboraram-se 
dois questionários. A análise estatística foi realizada através do Epi Info 7.2. Resultados: Verificou-se que os participantes conhecem a importância das boas práticas, já que $97 \%$ concordaram que a higienização é fundamental para evitar a transmissão de doenças. Porém $66 \%$ dos participantes afirmaram não saber como são realizadas as etapas de higienização. 0 APP foi bem aceito pelos avaliadores, sendo uma boa ferramenta de ensino. Conclusão: 0 desenvolvimento do APP mostrou-se viável na multiplicação de informações, devido à sua aceitação em todos os quesitos.

Palavras-Chave: Aprendizagem Móvel; Doenças Transmitidas por Alimentos; Manipulação de Alimentos; Saúde Móvel.

\section{Abstract}

Introduction: Advances in technology are promoters and facilitators of knowledge, and may contribute to the health sector. As food, safe food handling and nutrition are basic requirements for health promotion, technologies are a good alternative to provide adequate and up-to-date information on food. Theoretical Reference: This study is based on the principle of food and nutrition security. Objective: Report the construction and evaluation of an application for the dissemination of good food handling practices. Method: We selected five categories to compose the APP, with five sessions each. We developed SafeFood based on the Java Script language and the React Native framework. We prepared two questionnaires to evaluate the acceptance and the participants' knowledge. Statistical analysis was performed by Epi Info 7.2. Results: The evaluation showed that the participants know the importance of good practices since $97 \%$ agreed that hygiene is essential to prevent the transmission of diseases, as in other aspects. However, $66 \%$ of the participants said they don't know how to perform the hygiene and respective steps. The APP was well accepted and evaluated and can be considered a good teaching tool. Conclusion: Thus, the development of the Application proved viable in the multiplied information. It's due to its acceptance in all aspects.

Keywords: Mobil Learning; Foodborne Diseases; Food Handling; Mobile Health.

A pesquisa foi aprovada pelo Comitê de Ética em Pesquisa da Universidade de Pernambuco, Recife-Pernambuco, sob o número: 06831518.0.0000.5207.

\section{Introdução}

Os avanços na tecnologia são canais promotores e facilitadores para a aquisição de conhecimentos, podendo ser também grandes contribuintes para o setor da saúde, pois podem auxiliar na administração dos fatores necessários para alcançar o estilo de vida saudável ${ }^{1,2}$.Tal impacto já é notável em pesquisas sobre tecnologia móvel aplicada à saúde, que é, hoje, um campo de pesquisa em crescente expansão devido à popularização dos smartphones, tablets e suas ferramentas computacionais, sendo os aplicativos softwares projetados especificamente para plataforma móvel ${ }^{3}$. Essa popularização está associada à disponibilidade dos dispositivos móveis 24 horas por dia e à facilidade de acesso, já que podem ser transportados de um ambiente para outro4.

A utilização de aplicativos móveis no campo da saúde vem se mostrando uma ferramenta promissora para auxiliar os profissionais e pacientes na sua prevenção e no seu tratamento ${ }^{5}$. Os aplicativos móveis são ferramentas de fácil acesso, disponíveis em tempo 
integral e bastante utilizadas pela rapidez em seu processamento e pelo baixo custo ao usuário, tornando-os instrumentos digitais práticos em sua aplicação ${ }^{6}$.

Neste contexto, a alimentação e a nutrição são requisitos básicos para a promoção e proteção da saúde, possibilitando o crescimento e o desenvolvimento do ser humano. Segundo o Ministério da Saúde, a incidência de doenças relacionadas ao consumo de alimentos contaminados cresce anualmente ${ }^{7}$. Sendo assim, essas tecnologias são boas alternativas no fornecimento de informações adequadas e atualizadas quanto à alimentação. Seu uso incentiva uma atitude voluntária e consciente de consumo para a nutrição, já que está relacionado à escolha, à quantidade, à conservação e ao preparo dos alimentos ${ }^{1,8}$.

Uma etapa indispensável, antes da alimentação, é a higiene dos alimentos, pois essa prática pode reduzir a propagação de surtos de doenças de origem infecciosa ou tóxica, causadas pelo consumo de alimentos contaminados, ainda considerados problema de saúde pública mundial ${ }^{9}$. Neste sentido, esta etapa também se insere no conceito de segurança alimentar, pois, de acordo com o Conselho Nacional de Segurança Alimentar e Nutricional (CONSEA), a Segurança Alimentar e Nutricional é direito de todos os cidadãos, em qualidade e quantidade suficiente ${ }^{10}$. As condições como se encontram os alimentos são indispensáveis para a promoção e manutenção da saúde, já que o consumo destes com qualidade contestável e em condições higiênico-sanitários irregulares são fontes potenciais de contaminação ${ }^{3}$.

No Brasil, entre 2009 e 2018, segundo o Ministério da Saúde, registraram-se cerca de 6.809 surtos, quase o dobro, se comparado ao levantamento realizado entre 2000 e 2011, quando foram registrados 1.340 casos, segundo o Sistema de Informações de Agravos e Notificações (SINAN) e a Portaria n 204, de 17 de fevereiro de 2016, do Ministério de Saúde 7. Dentre os 120.584 doentes resultantes dos surtos, a maioria contraiu as doenças em suas residências (38,9\%), mostrando que, mesmo com ações de saúde em prática e com a constante renovação do conhecimento a partir das pesquisas nas universidades, o conteúdo não consegue atingir a população de forma geral ${ }^{8}$.

Em virtude do exposto, ao observar o impacto para a saúde da população, dado o déficit de informação, e a dificuldade existente em expor e facilitar o acesso às pesquisas ao público em geral, o presente estudo tem por objetivo relatar a construção e avaliação de um aplicativo para divulgação das boas práticas de manipulação de alimentos. Acredita-se ser esta uma via de transmissão de conteúdo científico de forma didática e aplicável, que 
permite a propagação da segurança alimentar e nutricional e viabiliza potencial redução dos surtos alimentares nas residências e empresas manipuladoras de alimentos.

\section{Métodos}

O projeto de desenvolvimento do aplicativo em boas práticas constitui-se como um estudo transversal quali-quantitativo organizado em quatro etapas: planejamento, construção, publicação e avaliação.

\subsection{Planejamento, construção e disponibilização do aplicativo para a população}

A primeira etapa (Figura 1), o planejamento, foi o momento para se definir o conteúdo a ser apresentado e o modo como poderia ser exposto. De forma sucinta, foram selecionadas cinco categorias para compor o conteúdo para o aplicativo (APP): mãos, utensílios, frutas, hortaliças e leguminosas/enlatados, que compõem a interface do menu principal. Dentro dessas categorias, foram organizadas divisões pontuais e componentes com o conteúdo distribuído em seções.

De forma geral, as informações foram distribuídas em cinco seções (lavagem, desinfecção, enxágue, secagem e armazenamento) com variações de acordo com a categoria, optando por dispor as instruções em frases curtas e de fácil compreensão para atender a um público amplo, e adicionadas imagens, que foram realizadas no Laboratório 2 de Nutrição da Universidade de Pernambuco, campus Petrolina.

A categoria de antissepsia das mãos contou com as informações distribuídas em nove passos, segundo a RDC ${ }^{11}$. A categoria frutas contou com 18 frutas, selecionadas de acordo com a disponibilidade em todo território nacional e regional (Nordeste), como: abacate, goiaba, abacaxi, laranja, tangerina, maçã, manga, maracujá, abóbora, mamão, melancia, melão, kiwi, morango, uva, caju, acerola e limão, seguindo os procedimentos descritos na Portaria CVS n 5, de 09 de abril de 2013, Diretora Técnica do Centro de Vigilância Sanitária da Secretaria de Estado da Saúde, Estado de São Paulo ${ }^{12}$.

A terceira categoria inclui utensílios, expondo todo o processo de higienização, devido à evidente importância da desinfecção desses materiais, pois, quando não higienizados, podem levar a risco de contaminação cruzada. Ela conta com 5 utensílios: copo, prato, vasilhas, talher e esponja, exemplificando lavagem, desinfecção, enxágue e secagem. A quarta categoria conta com o grupo das hortaliças escolhidas pela estação de cultivo no 
Brasil e no Nordeste, estruturada com 7 hortaliças, sendo elas acelga, batata, cenoura, tomate e pimentão, demostrando todo o processo de lavagem, desinfecção, enxágue, secagem e armazenamento ${ }^{12}$.

As leguminosas foram selecionadas também conforme já descrito para os demais vegetais. Os produtos enlatados estão associados, assim como a categoria de utensílios, para salientar sua importância no processo de higienização, sendo eles meio de contaminação se não forem devidamente desinfectados ${ }^{12}$.

A construção, ou seja, a programação para a criação do aplicativo SafeFood, foi desenvolvida baseada na linguagem Java Script e no framework React Native. Através de softwares de código fonte e simulação, como o Microsoft Visual Studio, Android Studio, Node Js, o aplicativo foi escrito e testado para somente oferecer suporte à plataforma Android, tanto para tablet quanto para smartphone. O banco de dados comporta-se estático, formado por fotos e ícones produzidos conforme já descrito. 0 aplicativo SafeFood foi disponibilizado para ser baixado para qualquer versão Android através do play store (https://play.google.com/store/apps/details?id=com.nutricaoappsf) logo após sua finalização para armazenamento e distribuição, permitindo o acesso dos usuários e a realização da fase de avaliação do APP.

0 código fonte encontra-se disponível na plataforma bitbucket (https://bitbucket.org/adhmattheus/safefooapp/src/master/) para atualizações futuras, quando necessárias.

\subsection{Análise do SafeFood pela população}

Após a disponibilização do APP, foi realizado um pré-teste com os transeuntes da Universidade de Pernambuco, campus Petrolina, os quais foram avaliados quanto ao conhecimento prévio sobre os procedimentos de higienização de alimentos e sobre doenças transmitidas por alimentos. 0 questionário foi estruturado de forma a conter 7 perguntas com respostas com escolha de apenas uma resposta (1. Sim ou 2. Não), sendo elas: “Na sua opinião, os alimentos devem ser higienizados antes do armazenamento?"; "A higienização dos alimentos realizada antes do armazenamento seria a forma correta?"; "O processo de higienização dos alimentos deve ser realizado de forma separada?” ; “O processo de higienização dos alimentos se dá por etapas, essas etapas são de fundamental importância para evitar a transmissão de doenças?", "Você sabe o que são DTAs?"; "Na sua opinião, os alimentos podem ser veículos de transmissão de doenças?"; e "Você sabe como 
é o processo de higienização dos alimentos?". Apenas uma questão ("Para você, quais são as etapas de higienização dos alimentos?") foi discursiva, para que o participante pudesse descrever quais etapas acreditava fazerem parte do processo de higienização. Para a caracterização da população, foram solicitados dados demográficos, como sexo, escolaridade e ocupação.

No pós-teste, foi utilizado o questionário contendo 8 afirmativas ("É fácil entender o conteúdo exposto no aplicativo; O conteúdo exposto é relevante; As informações sobre higiene de frutas e verduras seriam úteis na sua casa; As informações sobre higiene de utensílios seriam úteis na sua casa; 0 aplicativo é uma boa forma de transmitir conhecimento; É fácil aprender a usar o APP; O aplicativo tem layout atrativo; As imagens têm boa visibilidade"). Estas foram avaliadas segundo escala Likert de 5 pontos (1 discordo fortemente, 2 discordo, 3 concordo em partes, 4 concordo, e 5 concordo fortemente). A interface do SafeFood pode ser visualizada na Figura 2.

\subsection{Análise Estatística}

A construção do banco de dados ${ }^{1}$ deu-se no Excel (Versão 1910 Microsoft Office 365 ProPlus), e a análise estatística foi realizada através do Epi Info 7.2 (Versão 7.2.3.1, 28 junho 2019, CDC), com utilização do teste $X^{2}$ e do Prisma Version 5.0 (GraphPad, USA) com aplicação da estatística descritiva (média e desvio padrão) com valor de $p<0,05$.

\section{Resultados}

\subsection{Caracterização da população}

Ao avaliar as características demográficas, constatou-se que a população foi composta por $64 \%$ de mulheres e $36 \%$ de homens (Tabela 01 , em anexo). Isso se dá ao fato de que a participação das mulheres em pesquisas científicas é de maior adesão quando se compara ao público masculino ${ }^{13}$. Quanto à escolaridade, 70,6\% eram estudantes de ensino superior incompleto com cursos da área da saúde; $24,2 \%$ estudantes do ensino superior incompleto com cursos em outras áreas; $4,6 \%$ ensino superior completo com pós-graduação e $0,5 \%$ ensino médio completo. Estes resultados podem ser justificados devido à pesquisa ter sido realizada em ambiente universitário com prevalência de discentes das áreas de

1'Link para o banco de dados: https://docs.google.com/spreadsheets/d/10jixnbIPKM3CjzwA1Lhjl_A_OjRgIMnvmi17EZt0JY/edit?usp=sharing 
saúde e humanas. Em relação à ocupação, 95,4\% foi representado por estudantes de ensino superior que se dedicam exclusivamente a esta atividade; $2,55 \%$ são professores universitários; 0,5\% assistente administrativo e 0,5\% estudante do ensino médio. Com relação à idade, verificou-se que 64,4\% possuíam de 18 a 20 anos, 25,7\% de 21 a 30 anos, $4,65 \%$ de 31 a 40 anos e 0,52\% maior que 40 anos ( $<0,001)$. Estes resultados refletem o fato de os ingressantes serem geralmente jovens com idades de 18 a 34 anos, conforme descrito pelo Ministério da Educação ${ }^{14}$.

\subsection{Análise Pré-teste}

Após a aplicação do pré-teste, constatou-se que pelo menos $96 \%(n=187)$ dos participantes concordaram que os alimentos devem ser higienizados antes do armazenamento, como também 93\% ( $n=178)$ acreditaram que os processos da higienização devem ocorrer separadamente, e $99 \%(n=181)$ creram que os alimentos podem ser veículos de transmissão de doenças. Neste contexto, 97\% ( $n=193)$ acharam que as etapas da higienização são fundamentais para evitar a transmissão de doenças.

Estes dados podem ser explicados pelo fato de a maior parte dos entrevistados pertencerem a cursos da área da saúde, tendo eles um conhecimento prévio acerca do que foi abordado em questão. Apesar das respostas positivas a estas questões, ao serem questionados sobre os procedimentos corretos de higienização dos alimentos ("Você sabe como é o processo de higienização dos alimentos?" e "Você sabe o que são doenças transmitidas por alimentos?" ), 66\% ( $n=128)$ dos participantes afirmaram não saber como é realizada a higienização e quais são as respectivas etapas, o que foi confirmado pela questão discursiva: "Para você, quais são as etapas de higienização dos alimento?", 23,9\% $(n=45)$ responderam de forma incompleta ou com passos não condizentes com o recomendado. Algumas destas respostas foram: "Lavar com detergente neutro e água"; "Lavar com água corrente e guardar”; "Apenas lavar antes de armazenar ou consumir”; “Lava e come"; "Processo de lavar os alimentos com água corrente ou esterilização de recipientes de compotas"; "Lavar só se for frutas ou legumes"; "Imersão em vinagre, lavar com detergente e enxágue"; "Lavar, ferver ou deixar de molho por um tempo"; "Lavar em água corrente e sabão"; "Tirar da embalagem, lavar, dependendo de o alimento utilizar produto como vinagre”; “Jogar água, ensaboar e enxaguar”.

Resultados semelhantes também foram observados por Fortunato e Vienzi (2014), no estudo sobre conhecimentos de higiene na manipulação de alimentos em residências, 
verificando-se que $48 \%$ dos participantes da pesquisa alegaram não ter conhecimento sobre doenças de origem alimentar ${ }^{4}$. Porém, no citado estudo, 95\% dos participantes também mostraram o interesse em aprender mais sobre o assunto. Estes dados demonstram que 0 desenvolvimento do aplicativo objeto do presente trabalho vai ao encontro da necessidade explicitada pela população. Além disso, $45 \%(n=87)$ dos entrevistados afirmaram não saber o que são doenças transmitidas por alimentos, conforme pode ser visualizado na Figura 3. Considerando a realidade em que $37 \%$ dos surtos ocorrem em residências, segundo dados do Ministério da Saúde e do Sistema de Informação de Agravos de Notificação (SINAN), é crucial que a informação sobre estas doenças e suas prevenções seja dissipada de forma didática e prática, como propõe o aplicativo SafeFood ${ }^{8}$.

\subsection{Análise Pós-teste}

Sendo o aplicativo um instrumento para fornecer informações seguras sobre boas práticas de manipulação de alimentos, é importante avaliar não somente o conteúdo disposto, mas, se a forma utilizada atende as necessidades do receptor, considerando tanto o texto como layout, usabilidade e imagens dispostas, como visualizado na Figura 4. Assim, $100 \%$ dos voluntários $(n=194)$ concordaram que o aplicativo SafeFood é de fácil compreensão, assim como o seu conteúdo. Para atestar a aceitabilidade do aplicativo a longo prazo, foi questionado se o conteúdo é relevante: pelo menos $78 \%(n=151)$ concordaram fortemente, $18 \%(n=36)$ concordaram e $4 \%(n=7)$ apenas concordaram em partes. Com o intuito de avaliar se o aplicativo apresenta conteúdo relevante ("As informações sobre higiene de frutas e verduras seriam úteis na sua casa?"), 95\% (n=186) dos participantes concordaram que as informações sobre a higiene de frutas e verduras são úteis. Percentual semelhante ao avaliarem se as informações sobre a higiene de utensílios são úteis ("As informações sobre higiene de utensílios seriam úteis na sua casa), $96 \%$ (n = 180).

A concepção de que as informações sobre higiene são de grande importância e utilidade pode ser confirmada pelo fato de que as boas práticas de manipulação de alimentos propiciam a elaboração de alimentos inócuos, pois a maioria dos surtos de doenças transmitidas por alimentos (DTA) acontecem nos domicílios e desenvolvem-se por falhas no processo de higienização, contaminação cruzada, higiene pessoal deficiente, limpeza inadequada dos equipamentos e utensílios ${ }^{7}$. 
A fim de avaliar se o APP SafeFood constitui um veículo de fácil transmissão de conhecimento, $87 \%(n=169)$ responderam positivamente (concordo fortemente) a pergunta: 0 aplicativo é uma boa forma de transmitir conhecimento?". A usabilidade e o layout foram aprovados por $99 \%(n=193)$ dos participantes. Com relação à qualidade das imagens, 93\% ( $n=181$ ) concordaram que são de boa visibilidade. Estes dados são condizentes com os aspectos importantes para fixação, pois, de acordo com Carlos et al (2016), a associação de texto com imagem promove uma interação entre o conteúdo e o usuário, resultando em uma rápida aprendizagem, o que também irá promover a saúde proposta por cada aplicativo ${ }^{15}$. Esses pontos garantem autonomia, sendo um grande potencial para a educação em saúde, já que pode ser uma ferramenta no auxílio de prevenção de doenças ${ }^{15}$.

De forma geral, o APP foi bem aceito e avaliado podendo ser considerada uma boa ferramenta de ensino e aprendizagem. Além disso, foi dada a oportunidade para os participantes opinarem quanto ao melhoramento do APP, como mostram os exemplos: "Verificar a possibilidade de acessibilidade, visto que, se houvesse a possibilidade de ter som descrevendo as etapas, seria mais interessante"; "Expandir o aplicativo para creches, restaurantes e escolas"; "Expandir para pessoas com deficiência”; "Iniciar o APP com um vídeo tutorial". Estas sugestões serão avaliadas para possível atualização e aperfeiçoamento do aplicativo.

\section{Conclusão}

A prevenção é a melhor e a mais eficaz forma para evitar as DTA, tornando-se assim de extrema relevância a criação do APP para a população em geral, mostrando os estudos realizados pelo Ministério da Saúde junto ao SINAN que os maiores índices de incidências dessas doenças acontecem nas residências.

A construção do aplicativo foi pensada como forma de auxiliar a população com uma ferramenta de fácil acesso, gratuita e didática para disseminar o conhecimento sobre o processo de higienização, desinfecção e armazenamento dos alimentos e utensílios. 0 desenvolvimento do aplicativo em boas práticas de alimentação apresentou potencial como multiplicador de informações didáticas sobre higiene dos alimentos para a população em geral, conforme os resultados encontrados. 
Desse modo, o aplicativo SafeFood demonstrou que pode auxiliar na aprendizagem das boas práticas de manipulação, podendo dar suporte às etapas de higienização dos alimentos e utensílios, evidenciando sua viabilidade na proteção da saúde.

Esses dados mostram a possibilidade de inserir demais informações essenciais à saúde no aplicativo SafeFood e de desenvolver novas pesquisas neste sentido.

Como isso, espera-se o desenvolvimento de novos métodos que disseminem o conhecimento de práticas promotoras de saúde para a população e de ferramentas que explorem os conteúdos assimilados pelos discentes em prol de sua comunidade.

\section{Referências}

1. Fernandes MP, Marin H de F. Uso de aplicativos móveis para o controle de dietas em adultos : uma Revisão Sistemática Integrativa. Journal of Health Informatics. 2018;10(4):119-24.

2. Granado-Font E, Flores-Mateo G, Sorlí-Aguilar M, Montaña-Carreras X, Ferre-Grau C, Barrera-Uriarte ML, et al. Effectiveness of a Smartphone application and wearable device for weight loss in overweight or obese primary care patients: Protocol for a randomised controlled trial. BMC Public Health. 2015;15(1):2-7.

3. Tibes CM dos S; Dias JD; Zem-Mascarenhas SH. Mobile applications developed for the health sector in Brazil: an integrative literature review. REME rev. min. enferm ; 18(2): 471478, abr.jun.2014;(3):1-21.

4. Fortunado LH, Vicenzi K. Practical knowledge of food hygiene and handling in the residences of residents of Caxias do Sul - RS. Revista UNINGÁ. 2014;17(1):42-7.

5. Baldo C, Zanchim MC, Ramos Kirsten V, Bertoletti De Marchi AC. Diabetes Food Control - Um aplicativo móvel para avaliação do consumo alimentar de pacientes diabéticos.

Revista Eletrônica de Comunicação, Informação e Inovação em Saúde. 2015;9(3):1-12.

6. Cristina $\mathrm{H}$, Frizzo F. $\mathrm{O}$ uso de tecnologias virtuais no cuidado à criança e ao adolescente com câncer: Revista de Saúde Digital e Tecnologias Educacionais. 2019;4(1):43-59.

7. Ministério da Saúde. Doenças Transmitidas por.

Http://Portalsaude.Saude.Gov.Br/Images/Pdf/2015/Julho/01/Arquivo-1-Dta.Pdf. 2010. $160 \mathrm{p}$.

8. BRASIL. Ministério da Saúde. por Alimentos no Brasil Conceito. Secretaria de Vigilância em Saúde. 2019;16.

9. World Health Organization. Foodborne diseases.

https://www.who.int/foodsafety/areas_work/foodborne-diseases/en/

10. CONSEA. Legislação Básica do Sistema Nacional de Segurança Alimentar e Nutricional. 2017. 0-85 p.

11. BRASIL. Agência Nacional de Vigilância Sanitária (ANVISA). Resolução RDC $n^{\circ} 42$, de 29 de agosto de 2013. Dispõe sobre o Regulamento Técnico MERCOSUL sobre Limites Máximos de Contaminantes Inorgânicos em Alimentos. Diário Oficial da República Federativa do Brasil. 2013;33-5.

12. Secretaria Estadual de Saúde do Estado de São Paulo. Diretora Técnica do Centro de Vigilância Sanitária da Secretaria de Estado da Saúde. Portaria CVS n 5, de 09 de abril de 2013. Aprova o regulamento técnico sobre boas práticas para estabelecimentos comerciais de alimentos e para serviços de alimentação, e o roteiro de inspeção, anexo. 
Diário Oficial do Estado, 19 de abril de 2013, nº. 73, Poder Executivo, l; 32 - 35.

13. Cunha MB, Ritter Peres OM, Giordan M, Bertoldo RR, de Quadros Marques G, Duncke AC. As mulheres na ciência: $O$ interesse das estudantes brasileiras pela carreira científica. Educacion Quimica. 2014;25(4):407-17.

14. Salata A. Ensino Superior no Brasil das últimas décadas: redução nas desigualdades de acesso? Tempo Social. 2018;30(2):219-53.

15. Carlos D de AO, Magalhães T de O, Filho JEV, da Silva RM, Brasil CCP. Concepção e Avaliação de Tecnologia mHealth para promoção da saúde vocal. RISTI - Revista Iberica de Sistemas e Tecnologias de Informacao. 2016;(19):46-60. 


\section{Anexos}

Tabela 01. Caracterização da população. Petrolina, Pernambuco, 2019.

\begin{tabular}{lcc}
\hline Variável & N & $\%$ \\
\hline Idade & 125 & 64,4 \\
$18-20$ anos & 50 & 25,7 \\
$21-30$ anos & 9 & 4,64 \\
$31-40$ anos & 1 & 0,52 \\
$>40$ anos & & \\
Sexo & 70 & 36,0 \\
$\quad$ Masculino & 124 & 64,0 \\
Feminino & & \\
& & \\
Escolaridade & 9 & 4,6 \\
Superior Completo Pós- & 137 & 70,6 \\
graduação & 47 & 24,2 \\
Superior Incompleto Área da & 1 & 0,5 \\
Saúde & & \\
Ensino Incompleto Outra Área & & 2,55 \\
Ensino Médio Completo & 6 & 95,4 \\
& 187 & 0,5 \\
Ocupação & 1 & 0,5 \\
$\quad$ Professores Universitários & 1 & \\
Estudantes Ensino Superior & & \\
Assistente Administrativo & Estudante Ensino Médio &
\end{tabular}

Fonte: os autores

Figura 1: Etapas de realização do trabalho. Petrolina, Pernambuco, 2019.

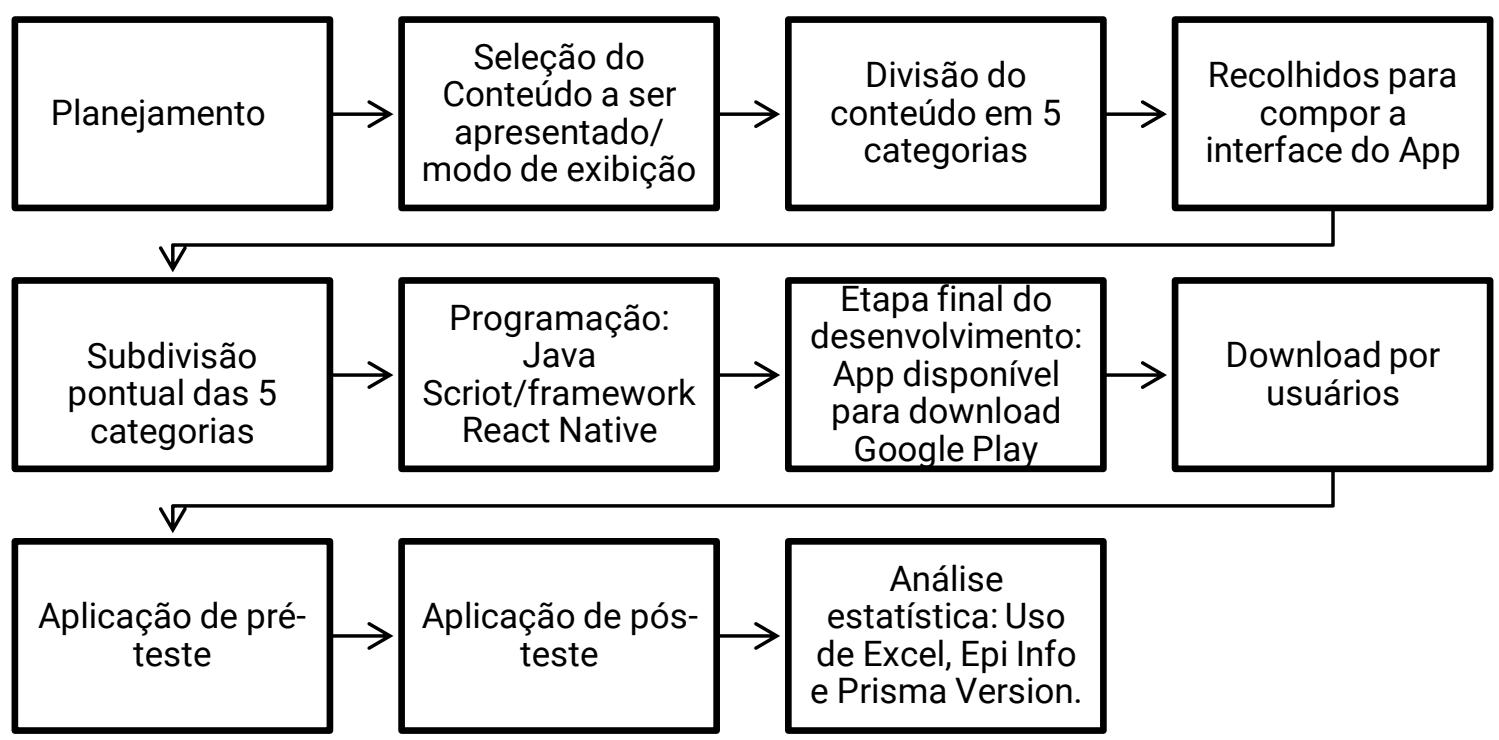

Fonte: os autores 
Figura 2. Interface do SafeFood. Petrolina, Pernambuco, 2019.

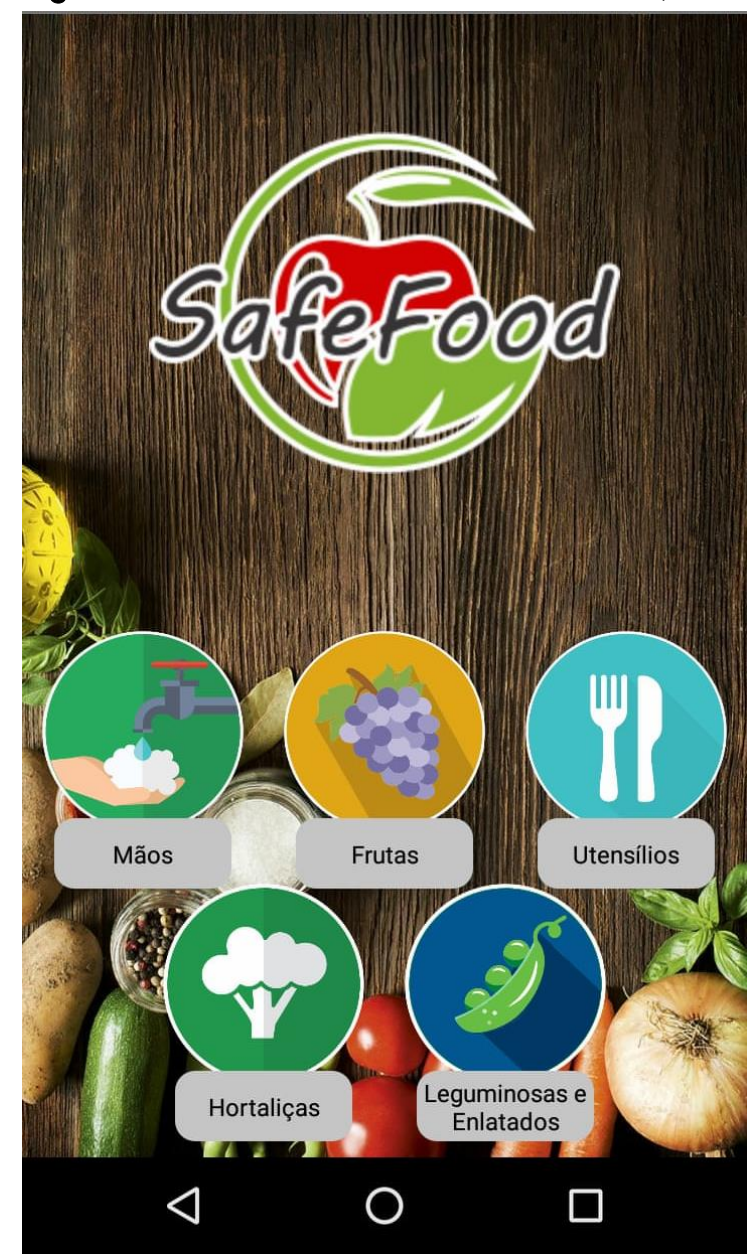

Fonte: os autores

Figura 3: Avaliação do conhecimento prévio sobre as boas práticas de manipulação de alimentos. Petrolina, Pernambuco, 2019.

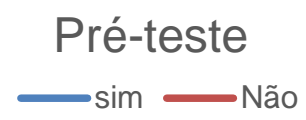

Higienização antes do

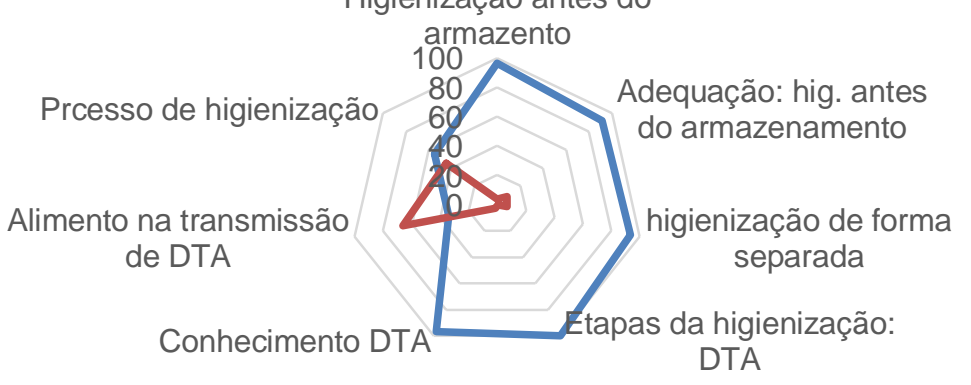

Fonte: Os autores, 2019. 
Figura 4: Avaliação do aplicativo SafeFood quanto à interface, ao conteúdo, à usabilidade, e à linguagem. Petrolina, Pernambuco, 2019.

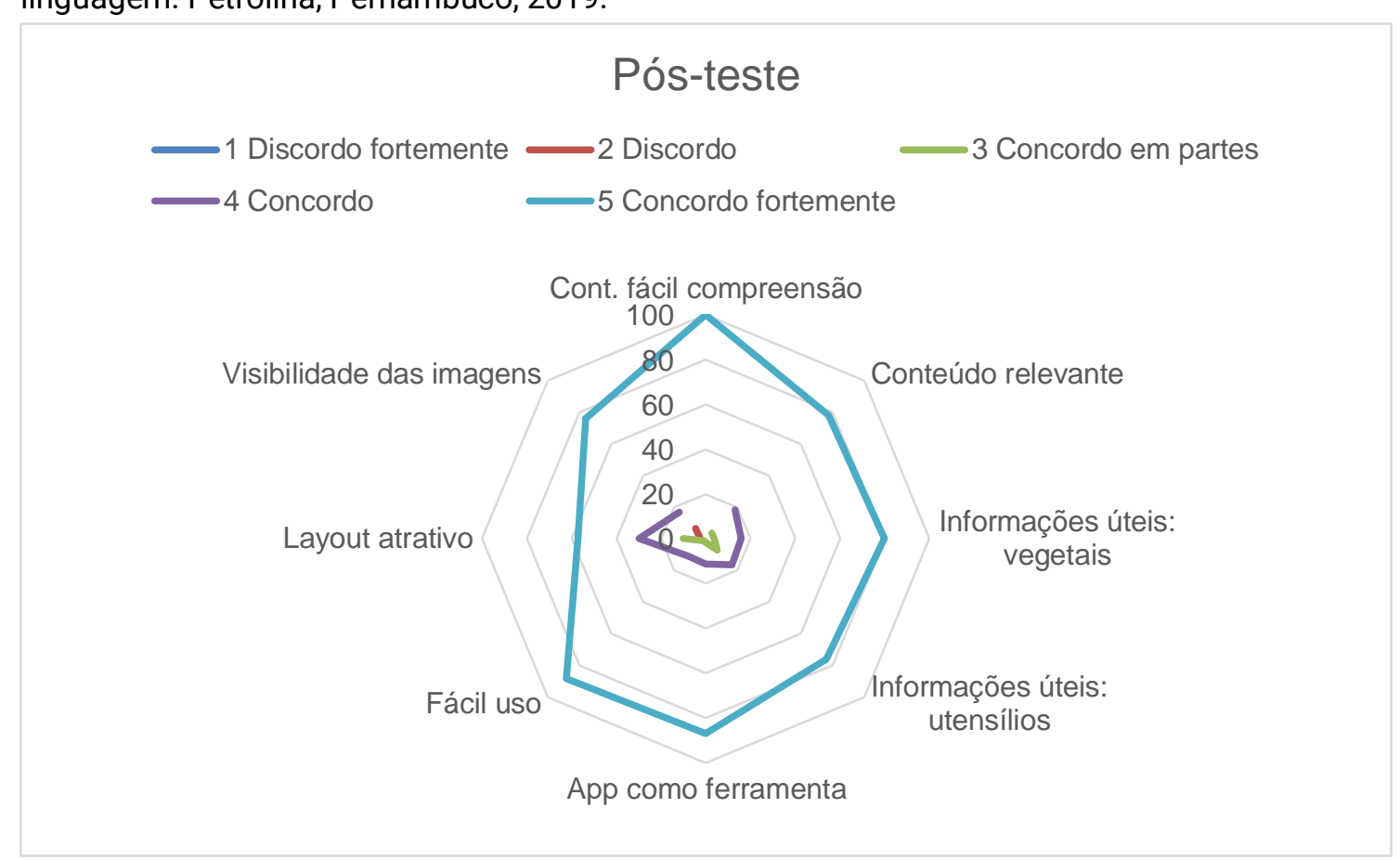

Fonte: Os autores, 2019 